\title{
Vasopressin-independent mechanisms in controlling water homeostasis
}

\author{
Carrie Y Y Cheng*, Jessica Y S Chu* and Billy K C Chow \\ School of Biological Sciences, The University of Hong Kong, Pokfulam, Hong Kong SAR, People's Republic of China \\ (Correspondence should be addressed to B K C Chow; Email: bkcc@ hkusua.hku.hk) \\ *(C Y Y Cheng and J Y S Chu contributed equally this work)
}

\begin{abstract}
The maintenance of body water homeostasis depends on the balance between water intake and water excretion. In the kidney, vasopressin $(\mathrm{Vp})$ is a critical regulator of water homeostasis by controlling the insertion of aquaporin 2 (AQP2) onto the apical membrane of the collecting duct principal cells in the short term and regulating the gene expression of AQP2 in the long term. A growing body of evidence from both in vitro and in vivo studies demonstrated that both secretin and oxytocin are involved as $\mathrm{Vp}$-independent mechanisms regulating the renal water reabsorption process, including the translocation and expression of AQP2. This review focuses on how these two hormones are potentially involved as $\mathrm{Vp}$-independent mechanisms in controlling water homeostasis.
\end{abstract}

Journal of Molecular Endocrinology (2009) 43, 81-92

\section{Introduction}

Osmoregulation involves sophisticatedly integrated physiological and behavioral responses to maintain the osmolality of the fluid bathing body cells. The regulation of renal handling of water and electrolytes by the antidiuretic hormone, vasopressin $(\mathrm{Vp})$, and the regulation of water and salt intake by the dipsogenic peptide, angiotensin, are involved in the physiological and behavioral approaches respectively. In recent years, many studies have shown that other hormones also exhibit anti-diuretic functions and these findings add to a growing body of evidence indicating the involvement of $\mathrm{Vp}$-independent mechanisms in regulating renal water reabsorption (Bauman 1965, Jeon et al. 2003, Li et al. 2006). Secretin (Waldum et al. 1980, Chu et al. 2007) and oxytocin (Brooks \& Pickford 1958, Jeon et al. 2003), were previously argued to exert either diuretic or antidiuretic effects, are therefore candidates in regulating renal functions. This review will focus on how these two hormones are potentially involved as Vp-independent mechanisms controlling water homeostasis.

\section{Current concepts in water regulation}

The maintenance of body water homeostasis depends on the balance between water intake and water excretion, with water intake being governed by the sensation of thirst and the availability of water, and water excretion controlled by the antidiuretic hormone $\mathrm{Vp}$ and the medullary osmotic gradient.

\section{Vasopressin}

$\mathrm{Vp}$ is a pleiotropic peptide which affects a wide range of peripheral and central regulated functions in order to conserve water in the kidney. It controls extracellular fluid osmolarity by adjusting the amount of free water excreted by the kidney and the main effect of $\mathrm{Vp}$ is found in the collecting duct where it causes insertion of aquaporin 2 (AQP2) water channels onto the apical membrane (Nielsen et al. 1993, 1995, Fushimi et al. 1997). AQP2 acts as a hydrophilic pore to move water transepithelially from the lumen to interstitium via $\mathrm{AQP} 2$ at the apical membrane and AQP3/AQP4 at the basolateral membrane.

In the kidney, $\mathrm{Vp}$ binds to a $\mathrm{G}$ protein-coupled receptor, Vp type 2 receptor (V2R), on the basolateral membrane of the collecting duct principal cells to stimulate the activity of adenylate cyclase, which subsequently increases intracellular cAMP levels and leads to the activation of protein kinase A (PKA). Activated PKA is then targeted to AQP2-bearing intracellular vesicles (IVs) by PKA anchoring protein 18- $\delta$ (Klussmann \& Rosenthal 2001), in which it phosphorylates $\operatorname{Ser}^{256}$ of AQP2 (van Balkom et al. 2002). 
Moreover, activated PKA could also phosphorylate Rho at $\mathrm{Ser}^{188}$ leading to an attenuation of Rho activity that favors depolymerization of F-actin (Tamma et al. 2003). This V2R- mediated signaling leads to the exocytic insertion of AQP-2-bearing vesicles onto the apical plasma membrane (PM), resulting in a high collecting duct water permeability and hence the osmotically driven water movement from lumen to the interstitium, achieving reabsorption of water in the kidney.

To compensate for the hypovolemic or hypernatremic state of the body, $\mathrm{Vp}$ also stimulates the expression of AQP2 and affects different regions of the nephron in addition to the stimulation of AQP2 translocation. Studies reported that Vp up-regulates the transcription of AQP2 gene through a cAMP response element in the AQP2 promoter (Hozawa et al. 1996, Matsumura et al. 1997). In addition, it was shown by Sands (2003), that Vp could assist in the high rates of trans-epithelial urea transport. Such transport is mediated by the PKA phoshorylation of the urea transporter A1 and/or A3, which are located in the terminal collecting duct in the inner medulla. This can bring large amount of urea into the inner medulla to maintain a high interstitial osmolarity resulting in maximized urine concentration.

Osmolar gradient between the medullary interstitium and the luminal fluid is the final determination of the amount of water being reabsorbed. The existence of a medullary hypertonic interstitium is ensured by the reabsorption of $\mathrm{NaCl}$ against its electrochemical gradient in the thick ascending limb of the loop of Henle. $\mathrm{Vp}$ could also induce $\mathrm{Na}^{+}$ reabsorption in the thick ascending limb as well as in the cortical and outer medullary collecting ducts, ensuring the existence of a medullary hypertonic interstitium for maximum water reabsorption. Vp exerts the natriferic response by inducing translocation of $\mathrm{Na}^{+}-\mathrm{K}^{+}-$ATPase from a brefeldin A-sensitive intracellular pool to the basolateral PM in the thick ascending limb and the cortical collecting ducts (Capurro 2001, Feraille et al. 2003), thus increasing the abundance of $\alpha, \beta$, and $\gamma$ subunits of the epithelial sodium channel in the cortical collecting ducts (Ecelbarger et al. 2000). In addition, Vp also increases phosphorylation of regulatory threonines in the amino terminus of $\mathrm{Na}-\mathrm{K}-\mathrm{Cl}$ cotransporter (NKCC2) and induces the trafficking of NKCC2 in the thick ascending limb (Gimenez \& Forbush 2003; Fig. 1).

\section{Collecting duct AQPs}

High water permeability in the collecting duct is required for the absorption of water out of the renal tubule. Transepithelial water transport across the collecting duct epithelium is generally believed to occur by a transcellular route with serial passages across the apical and basolateral PMs. A series of studies over the past ten years have clearly demonstrated that osmotic water transport across the tubule epithelium is chiefly dependent on AQP water channels, which are present in the apical (AQP2; Nielsen et al. 1993) and basolateral PM (AQP3, AQP4; Ishibashi et al. 1994, Ecelbarger et al. 1995, Terris et al. 1995). In both human and mouse models, the presence of AQP2 in apical PM was shown to be essential in the urinary concentrating mechanism (Deen et al. 1994b), however, only AQP3 null mice were markedly polyuric (Ma et al. 2000) and AQP3 null individuals did not suffer any obvious clinical syndromes (Roudier et al. 2002).

\section{AQP2}

AQP2 is widely expressed in all renal tubule segments. It is most abundant in principal cells of the collecting duct and less so in tubule cells of the connecting tubule or inner medullary collecting duct (IMCD; IMCD cells; Nielsen et al. 1993, Loffing et al. 2000). Within these cells, AQP2 is primarily found embedded in the apical $\mathrm{PM}$ and subapical vesicles, while it is also present in the basolateral PM, particularly in IMCD cells (Marples et al. 1995, Nielsen et al. 1995, Breton \& Brown 1998, Coleman et al. 2000).

It is generally agreed that $\mathrm{Vp}$ regulates the water permeability of the mammalian collecting duct and hence urine concentration via long term regulation of AQP2 abundance and short term induced translocation of the protein (Brown 2003). To further clarify the role of AQP2 in concentrating urine, a number of mouse models have recently been developed. A mouse knockin model of AQP2-dependent nephrogenic diabetes insipidus (NDI) was generated; the mouse line was created by using a Cre-loxP strategy to insert a T126M mutation into the AQP2 gene, resulting in blocked delivery of mature AQP2 protein to the apical PM (Yang et al. 2001). These knock-in mice generally died within 1 week of birth although they appeared outwardly normal. Other transgenic mouse models have also been developed to examine the role of AQP2 in the adult mouse. One model, developed by Rojek et al. (2006), makes use of the Cre-loxP system of gene disruption to create a collecting duct-specific deletion of AQP2, leaving relatively normal levels of expression in the connecting tubule. Another model developed by Yang et al. (2006) has an inducible AQP2 gene deletion in the kidney. These cell-specific mutants shared common phenotypes with severe polyuria and decreased urinary osmolarity. However, under free access to water, plasma concentrations of electrolytes, urea, and creatinine in knockout mice are comparable with the controls despite polyuria. Apparently, these 


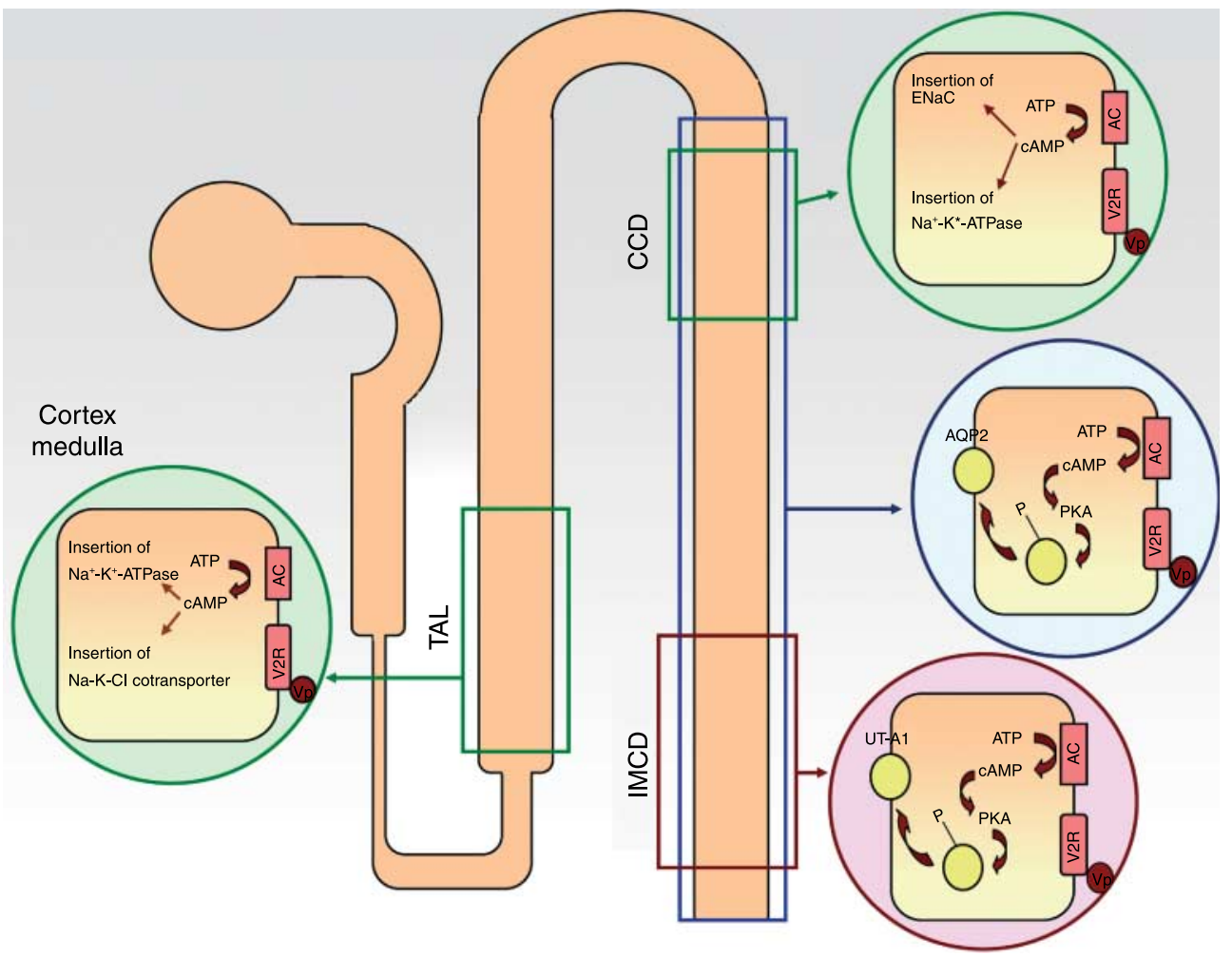

Figure 1 An overview of the multiple actions of vasopressin in conserving water in the kidney. In the collecting duct, Vp binds to V2 receptor (V2R) to initiate the synthesis of intracellular cAMP via $\mathrm{G}_{\mathrm{s}}$ /adenylyl cyclase (AC). The increased cAMP activates PKA which phosphorylates AQP2. This V2R-mediated signaling pathway eventually leads to exocytotic insertion of AQP2-bearing vesicles onto the apical plasma membrane. In the terminal inner medullary collecting duct (IMCD), Vp acts through PKA to increase the phosphorylation of the UT-A1 urea transporter. Vp exerts a natriferic effect via the same signaling pathway to induce the translocation of the $\mathrm{Na}-\mathrm{K}-\mathrm{Cl}$ cotransporter in the thick ascending limb (TAL), epithelial sodium channel $(\mathrm{ENaC})$ in the cortical collecting ducts (CCD) and $\mathrm{Na}^{+}-\mathrm{K}^{+}-\mathrm{ATPase}$ in both the CCD and TAL.

transgenic mice have normal renal function but are defective in urinary concentrating ability, thus implicating AQP2 in transcellular reabsorption of water in the collecting duct.

AQP2 regulates urine concentration under the control of $\mathrm{Vp}$, however, there is considerable evidence indicating the presence of Vp-independent mechanisms. For example, at maximal plasma levels of $\mathrm{Vp}$ at $10 \mathrm{pM}$ under severe dehydration, osmotic water permeability was at $44 \%$ of its maximal value (Star et al. 1988), suggesting that factors other than Vp could boost the osmotic water permeability to levels higher than that obtainable by Vp alone. Another group found that hyperosmolality in vivo in Vp-deficient Brattleboro rats would also increase expression and trafficking of AQP2 as well as urinary osmolality ( $\mathrm{Li}$ et al. 2006). As indicated in recent studies, secretin and oxytocin are essential components of the Vp-independent mechanism in kidney. Secretin is a classical gastrointestinal hormone and its major function is to stimulate electrolytes and water secretion from the intestine, liver, and pancreas. Oxytocin is released from the posterior pituitary to stimulate uterine contraction at parturition and mammary gland smooth muscle contraction during lactation. Both hormones have previously been argued to exert either diuretic or anti-diuretic effects and have recently been shown to stimulate AQP2 translocation, hence, are putative Vp-independent mechanisms in controlling water homeostasis.

\section{The pharmacological actions of secretin in the kidney}

The role of secretin and its receptor in regulating renal functions has been suggested but not fully substantiated in the past as inconsistent findings regarding the renal functions of secretin have been reported. Earlier studies suggested a diuretic role of this peptide in normal human subjects and dogs (Baron et al. 1958). Baron et al. (1958) and Alfredo et al. (1975) both noted that i.v. injection of secretin caused a rise in urinary 
volume and bicarbonate excretion in normal human subjects. Alfredo suggested that secretin had a direct effect on the renal tubule to decrease the reabsorption of water, bicarbonate, sodium, and chloride. Consistent with these results, Waldum et al. (1980) also observed a significant increase in urinary water, sodium, calcium, and solute excretion after the infusion of pure natural secretin. It was suggested that the impairment of sodium reabsorption in the renal tubule was the cause. In their study, secretin infusion caused a significant increase in renal plasma flow which may impair tubular sodium reabsorption. A rise in renal plasma flow could either be due to renal vasodilation or to cardiac output, or a combination of both, and earlier studies have showed a vasodilatory effect of secretin. They therefore concluded that the diuretic effect of secretin was most likely contributed by the impairment of sodium reabsorption in renal tubule caused by an increase in renal plasma flow as a result of dilation of the renal vascular bed. A consistent diuretic effect of secretin was also demonstrated in dogs (Dragstedt \& Owen 1931). Different secretin preparations were extracted from the mucosa of the first six feet of the hog's intestine and all these preparations were found to produce significant diuresis after i.v. injection into both anesthetized and unanesthetized dogs. A latent period of 20-30 min was observed after the injection, followed by a period of diuresis during which the increased flow varied from 50 to $100 \%$. Another study also demonstrated that i.v. infusion of $0.5 \mu \mathrm{g} / \mathrm{kg}$ min of pure synthetic secretin into conscious dogs resulted in diuresis and significant increases in sodium and potassium output (Barbezat et al. 1972).

Earlier reports consistently showed a diuretic effect of secretin, however, two later studies reported contradictory results. One of the studies showed that intravenously administrated secretin has an antidiuretic effect in rats (Charlton et al. 1986). The opposing results may be due to the usage of different animal models and/or peptide sources as well as the dosages of secretin being used. Charlton et al. argued that the diuresis was due to the reabsorption and renal excretion of secretin-induced secretion of pancreatic juice and bile. His argument was grounded on a previous study that reported that a decreased diuretic effect of natural secretin occurred in humans with chronic pancreatitis. He also suggested that the impurities of natural secretin used should be taken into account as the presence of an agent causing vasodilation has been reported with natural secretin.

Of all these studies on the renal effects of secretin, they concentrated on the pharmacological actions of secretin, leaving its physiological significance to remain uncertain. To elucidate further the renal effect of secretin, transgenic mouse models were recently generated to unfold the physiological action of secretin on renal water regulation (Chu et al. 2007). In this mouse model, exon 10 of the secretin receptor (SCTR) gene was replaced with a PGK-1 promoterneomycin resistance gene cassette, resulting in a nonfunctional receptor. These SCTR-null mice $\left(\mathrm{SCTR}^{-/-}\right.$) exhibited polyuria and polydipsia phenotypes; they drank $8 \cdot 0 \pm 0 \cdot 3 \mathrm{ml}$ water and produced $2 \cdot 3 \pm 0 \cdot 1 \mathrm{ml}$ urine, compared with $S C T R^{+/+}$ mice, which drank $5 \cdot 5 \pm 0 \cdot 3 \mathrm{ml}$ water and produced $1 \cdot 7 \pm 0.1 \mathrm{ml}$ urine. The urine osmolality of SCTR ${ }^{-/-}$ mice $\left(1897 \pm 59 \mathrm{mOsm} / \mathrm{kg} \mathrm{H} \mathrm{H}_{2} \mathrm{O}\right)$ was lower than that of $\mathrm{SCTR}^{+/+}$mice $\left(2374 \pm 57 \mathrm{mOsm} / \mathrm{kg} \mathrm{H} \mathrm{H}_{2} \mathrm{O}\right)$. In addition, SCTR ${ }^{-/-}$mice produced urine with reduced $\mathrm{Na}^{+}\left(S_{C T R}^{+/+}, 152 \pm 4 \cdot 7 \mathrm{mmol} / \mathrm{l} ; \mathrm{SCTR}^{-/-}\right.$, $124 \pm 5 \cdot 2 \mathrm{mmol} / \mathrm{l}), \mathrm{K}^{+}\left(S C T R^{+/+}, 349 \cdot 8 \pm 10 \mathrm{mmol} / \mathrm{l}\right.$; $\left.\mathrm{SCTR}^{-/-}, 285 \cdot 2 \pm 9 \cdot 4 \mathrm{mmol} / \mathrm{l}\right)$, urea $\left(S C T R^{+/+}\right.$, $\left.1339 \pm 43.6 \mathrm{mmol} / \mathrm{l} ; \mathrm{SCTR}^{-/-}, 1056 \pm 34 \mathrm{mmol} / \mathrm{l}\right)$, and creatinine level $\left(S_{C T R}{ }^{+/+}, 5566 \pm 312 \mu \mathrm{mol} / \mathrm{l}\right.$; $\left.\mathrm{SCTR}^{-/-}, 4504 \pm 232 \mu \mathrm{mol} / \mathrm{l}\right)$ compared with those of $S_{C T R} R^{+/+}$mice. This study strongly supports an antidiuretic function of secretin in rodents.

\section{Distribution of SCTR in kidney}

Previous studies regarding the presence of SCTR within the kidney were limited and inconsistent. Ulrich $e t$ al. (1998) indicated that there was no expression of SCTR in rat kidney using a RNase protection assay, whereas Ohta et al. (1992) and Chu et al. (2007) reported SCTR protein and transcript expression in rat and human kidneys by immunohistochemical staining and northern blot analysis respectively. Consistent with this, Charlton et al. (1986) found high density of $\left[{ }^{125} \mathrm{I}\right]$-secretin binding sites in the renal medulla by autoradiographic studies. By immunohistochemical stainings using $\mathrm{SCTR}^{-/-}$as negative controls, SCTR was found in the cuboidal epithelium of the collecting ducts and in the simple columnar epithelium of the ducts of Bellini. Additionally, it was also detected in the proximal tubules and the ascending thick segment of the Loop of Henle (Chu et al. 2007).

\section{SCT and SCTR are potentially involved as a Vp-independent mechanism conserving water in the kidney}

A previous study showed that i.v. administration of secretin caused a dose-dependent decrease in urine output, suggesting that secretin has an antidiuretic action in the kidney (Charlton et al. 1986). As microdissection studies demonstrated the presence of secretin-sensitive adenylyl cyclase in kidney membranes, and that secretin is as potent as $\mathrm{Vp}$ in homozygous Vp-deficient Brattleboro rats, it was postulated that 
secretin could act on its receptors in the renal medulla to decrease urine output through the activation of adenylate cyclase. In this notion, SCTR ${ }^{-/-}$mice were found to have defects in the urinary concentrating mechanism, suggesting that SCTR could function to adjust the amount of free water excreted by the kidney (Chu et al. 2007). The osmoregulatory role of secretin was further suggested by the observed increase in serum secretin levels during water deprivation (Oektedalen et al. 1982). Consistent with this, the plasma secretin level increases $1 \cdot 60 \pm 0 \cdot 03$-fold in mice under water deprivation, again indicating a role of secretin in water regulation (Chu et al. 2007). Plasma secretin concentration was found to increase three to sixfold during prolonged physical stress, resulting in an altered renal function. The increased plasma secretin concentration, however, could be reversed by the administration of hypertonic glucose solution which causes the retention of water (Oektedalen et al. 1982).

The transgenic mice study not only sheds light on the urine concentrating ability and the antidiuretic role of secretin, but also provides evidence that secretin could be one of the Vp-independent mechanisms controlling water homeostasis as this antidiuretic effect observed in transgenic mice was shown to be independent of Vp. The study showed that the serum Vp levels of the $\mathrm{SCTR}^{-/-}$is comparable with those of the $\mathrm{SCTR}^{+/+}$ mice under water ad libitum. In addition, there are no significant differences in the transcript levels of V2R in SCTR $^{-/-}$and SCTR ${ }^{+/+}$kidney (Chu et al. 2007), clearly showing the impaired urine-concentrating ability of SCTR ${ }^{-/-}$mice is not due to impaired response of kidney to Vp stimulation. The same study also indicated that there were significant reductions in the transcript levels of AQP2 and AQP4 in SCTR ${ }^{-/-}$kidneys while less AQP2 expression was triggered in $\mathrm{SCTR}^{-/-}$ mice under water deprivation. Taken together, secretin is a likely candidate as one of the Vp-independent mechanisms via regulation of AQP2.

\section{Secretin induces translocation and expression of AQP2 under water deprivation}

An increasing body of evidence has revealed that secretin may possess a renal effect. However, the key question concerning the mechanisms involved remains to be answered. The transgenic approach, thus, provides additional insight into the physiological action of secretin in water homeostasis and the underlying mechanism by which secretin exerts its activity.

Quantitative real-time PCR revealed significant reductions in the transcript levels of AQP2 and AQP4 (Chu et al. 2007) in SCTR ${ }^{-/-}$mice, suggesting that the impaired urine-concentrating ability of SCTR ${ }^{-1-}$ mice is at least partly due to the reduced levels of these AQPs.
AQP2, located on the apical membrane, concentrates urine by reabsorbing water, while AQP4, present on the basolateral membrane of the collecting tubules, represents a potential exit pathway for water entering via AQP2. The reductions in both transcript and protein levels of these water channels were consistent with the observed phenotypes developed in SCTR ${ }^{-/}$animals.

By examining the in vitro effects of secretin on the distribution of AQP2 in the inner medullary tubular cells of $\mathrm{SCTR}^{+/+}$and $\mathrm{SCTR}^{-/-}$mice, secretin was found to induce a dose-dependent increase in both glycosylated and non-glycosylated AQP2 proteins in the PM of medullary tubules in $\mathrm{SCTR}^{+/+}$mice $(\mathrm{Chu}$ et al. 2007). Quantification of the blots revealed a $2 \cdot 11 \pm 0 \cdot 15$-fold increase in the $\mathrm{PM} / \mathrm{IV}$ ratio of AQP2 after incubation with $10^{-8} \mathrm{M}$ secretin for $30 \mathrm{~min}$. This effect, however, was not observed in the medullary tubules isolated from $\mathrm{SCTR}^{-/-}$mice, clearly indicating the specificity of the actions of secretin via its receptor. We have recently repeated this experiment using inner medullary tubules isolated from the rat kidney in the presence of secretin $\left(10^{-10}-10^{-8} \mathrm{M}\right)$. We found that secretin could dose-dependently induce redistribution of AQP2 from the intracellular vesicles to plasma membrane, with a $2 \cdot 78 \pm 0 \cdot 40$-fold increase in $10 \mathrm{nM}$ secretin (Fig. 2A). The concentration of secretin being used is much higher than the basal plasma secretin concentration in rats $(1.8 \pm 0.5 \mathrm{pM} ; \mathrm{Li}$ et al. 2001), implicating the effect of secretin on AQP2 relocation at a pharmacological level. Moreover, co-treatment of a secretin antagonist $(1 \mu \mathrm{M}$ secretin5-27) and a cAMPdependent PKA inhibitor ( $5 \mu \mathrm{M}$ H89) could both abolish the secretin-induced relocation of AQP2 $1 \cdot 06 \pm 0 \cdot 08$-fold and $1 \cdot 31 \pm 0 \cdot 12$-fold respectively, indicating that secretin and Vp share similar cAMP/PKA signaling pathway in activating AQP2 trafficking.

The in vivo trafficking of AQP2 under chronic hyperosmotic conditions and the in vitro effect of secretin on the redistribution of AQP2 in renal tubules have also been investigated. Chu et al. (2007) observed significant differences in terms of trafficking and expression of AQP2 between SCTR ${ }^{-/-}$and $\mathrm{SCTR}^{+/+}$ under water-deprived conditions. Water deprivation for $60 \mathrm{~h}$ could trigger a $2 \cdot 27 \pm 0 \cdot 27$-fold increase in the shift of AQP2 from IVs to the PM and a $5 \cdot 90 \pm 1 \cdot 06$-fold increase in the AQP2 transcript level in $\mathrm{SCTR}^{+/+}$mice. These data suggest that the induced expression and redistribution of AQP2 during water deprivation were at least partially dependent on SCTR.

Similar to its role in promoting transepithelial solvent flux in cholangiocytes by activating AQP1 trafficking to the apical membrane, it appears that secretin and $\mathrm{Vp}$ alike induce expression of AQP2 under hyperosmotic conditions and stimulate trafficking of this water channel from intracellular vesicles to the plasma membrane in renal collecting tubules. 

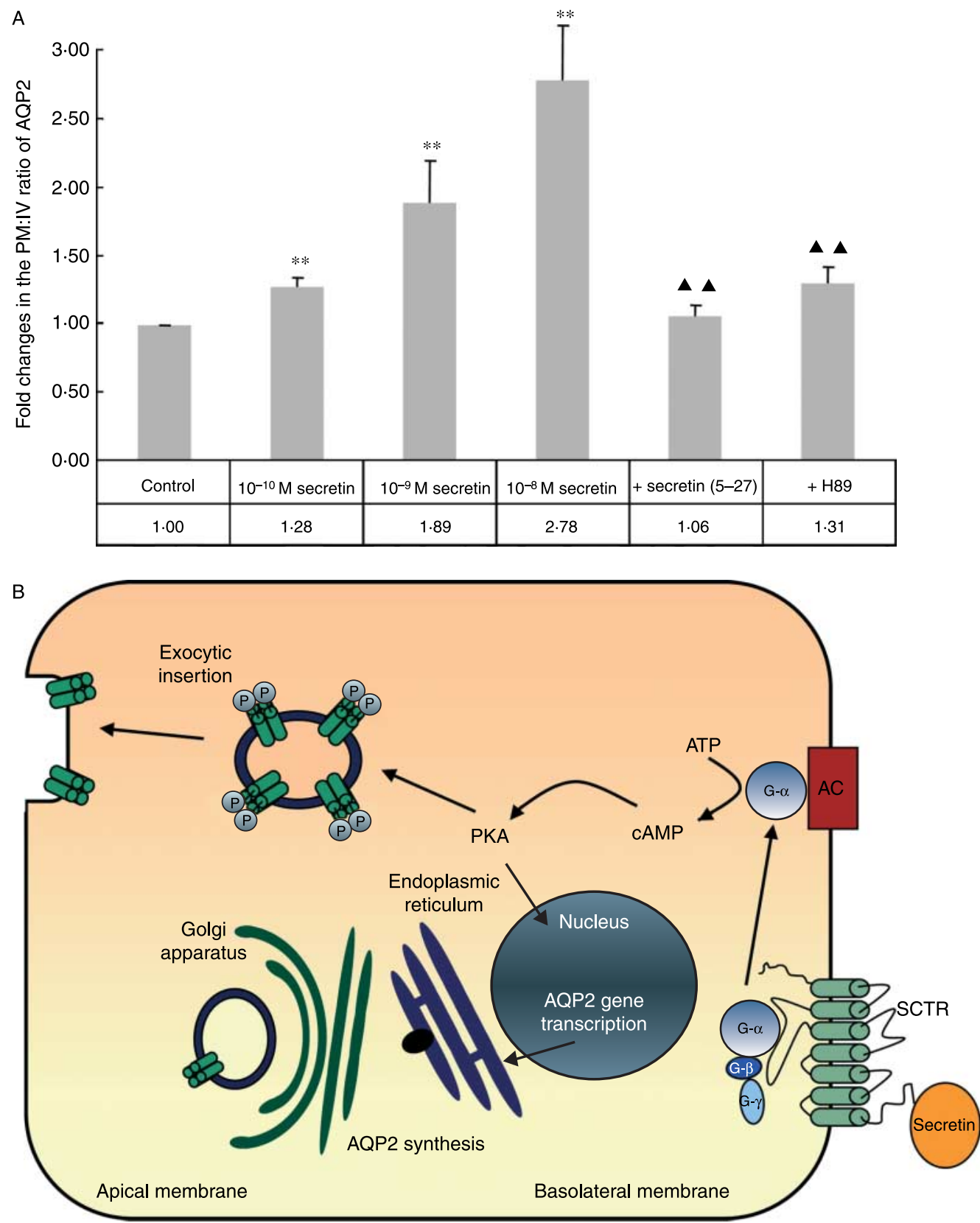

Figure 2 (A) Secretin induces subcellular redistribution of AQP2 from IV to PM in the inner medullar tubules suspension. Membrane fractions from the rat inner medullar were prepared $30 \mathrm{~min}$ post-drug treatment. Western blot and densitometric analysis were performed. Values were calculated from the mean pixel intensity measured from the 35 and $29 \mathrm{kDa}$ bands and were expressed as the fold change in ratios between the intensity of bands from plasma membrane (PM) and intracellular vesicles (IV). ${ }^{\star \star} P<0.01$ from the control group. $\Delta \wedge P<0.01$ from the $10^{-8} \mathrm{M}$ secretin treatment group. (B) Diagrammatic illustration of the effect of secretin in increasing water reabsorption in the principal cells of the collecting duct. Secretin increases intracellular cAMP levels via binding to SCTR on the basolateral membrane, which is coupled to adenylyl cyclase VI through the heterotrimeric G-protein, Gs. The increased cAMP leads to activation of PKA which subsequently phosphorylates AQP2. This SCTRmediated signaling leads to the exocytic insertion of AQP2-bearing vesicles into the apical plasma membrane. Secretin also participates in the long-term regulation of $A Q P 2$ via the $G_{s} / A C / P K A$ system, to phosphorylate unknown transcription factors resulting in an increase in both protein and transcript levels of AQP2. 
In conclusion, secretin plays a role in regulating body water homeostasis by exerting direct actions in renal system via regulating AQP2 trafficking. Recently, secretin has also been shown to translocate cystic fibrosis transmembrane regulator (CFTR) to the apical membrane in mouse cholangiocytes (Tietz et al. 2003). It is possible that secretin modulates renal water permeability via changing concentration of electrolytes in the interstitium by inducing CFTR translocation in a similar way as in cholangiocytes to facilitate active secretion of chloride ions.

\section{Oxytocin}

Oxytocin is well-established for its function in female reproduction. Oxytocin and $\mathrm{Vp}$ are closely related peptides, both are 9-amino-acid peptide hormones in which seven are identical, and are secreted from the posterior pituitary. Both of them form a cyclic structure via a disulfide linkage between cysteines in the first and sixth positions (Terashima et al. 1999). Owing to their similarities in structure and release site, the renal function of oxytocin has also been investigated.

\section{Anti-diuretic action of oxytocin}

Oxytocin was reported to exhibit both diuretic and antidiuretic activities depending on species, dosage, and metabolic status of the animal. In animal studies, oxytocin has consistently been reported to possess an anti-diuretic role at supraphysiological concentrations. Early studies showed that i.v. administration of oxytocin raised the urinary excretion of sodium two to fourfold and enhance glomerular filtration rate in dogs (Brooks \& Pickford 1958) and rats (Dicker \& Heller 1946). Recent studies using Vp-deficient Brattleboro rats showed that these animals could respond dose-dependently to oxytocin. At an infusion rate of $5 \mu \mathrm{g} / \mathrm{h}$ over a 7 -day period, oxytocin completely reversed symptoms of diabetes insipidus (Lyness et al. 1985). Similarly, using Brattleboro rats infused with oxytocin by an osmotic minipump for 5 days, marked antidiuresis, increased urine osmolality, and increased solute-free water reabsorption were observed ( $\mathrm{Li}$ et al. 2008). However, the anti-diuretic effect of oxytocin in humans is not proven. An early study showed that i.v. infusion of oxytocin with a dosage ranging from 4 to $200 \mathrm{mU} / \mathrm{min}$ produced no measurable anti-diuretic effects and led to insignificant changes of urinary excretion of sodium (Cross et al. 1960). On the other hand, another research group found an anti-diuretic effect in 15 out of 17 experiments using the same dosages of oxytocin (Thomson 1960). A recent study reported similar observations in both normal candidates and central diabetes insipidus (CDI) patients after oxytocin infusion and injection of 1-desamino-8-D-arginine Vp. These subjects showed significant decrease in free water clearance and urine flow and an increase in urine osmolality ( Joo et al. 2004). In addition, several cases of maternal hyponatremia and water intoxication were reported when oxytocin was employed to induce labor (Ahmad et al. 1975), thus, supporting the anti-diuretic action of oxytocin in humans. Further evidence was gathered by infusing graded doses of physiological plasma levels of oxytocin into rats maintained on a sodium-deficient diet, it was found that oxytocin doseindependently increased sodium excretion in rats (Verbalis et al. 1991) and osmotic water permeability (Pf) in isolated perfused terminal IMCDs in both Sprague-Dawley and Brattleboro rats. In summary, although there are conflicting findings, previous studies suggest that oxytocin can function physiologically as an antidiuretic hormone (Chou et al. 1995b).

\section{Oxytocin produces anti-diuresis by regulating AQP2}

A study documented, in vitro, that oxytocin caused a marked redistribution of the AQP-collecting duct water channels to a predominantly apical and subapical localization in IMCD cells in Brattleboro rats (Jeon et al. 2003). Using immunohistochemical staining, another study demonstrated that AQP2 translocates to the apical plasma membrane after either i.p. or osmotic minipump administration of oxytocin into Brattleboro rats (Li et al. 2008). This pattern of AQP2 redistribution was also noted in connecting tubule, cortical collecting duct, and outer medullary collecting duct (Jeon et al. 2003). Hence, although $\mathrm{Vp}$ is the principal factor in stimulating AQP2 trafficking in the kidney, oxytocin can apparently perform the same function as Vp (Fig. 3). The effects observed by subcutanceous injection of $20 \mu \mathrm{g}$ oxytocin and $10 \mu \mathrm{g} \mathrm{Vp}$ are comparable, both resulting in an increase in AQP2 expression in the collecting duct in Sprague-Dawley rats (Terashima et al. 1999). In Brattleboro rats, oxytocin administration was found to augment both protein and transcript levels of phosphorylated AQP2 and AQP3 (Li et al. 2008). Taken together, the anti-diuretic effects observed after pharmacological doses of oxytocin are at least partly due to trafficking of AQP2 and upregulation of AQP2 and AQP3.

\section{Oxytocin exerts its anti-diuretic effect via V2R}

Similar to their ligands, receptors for oxytocin and $\mathrm{Vp}$ share structural homology and are G protein-coupled receptors. As oxytocin can also bind to Vp receptor but 


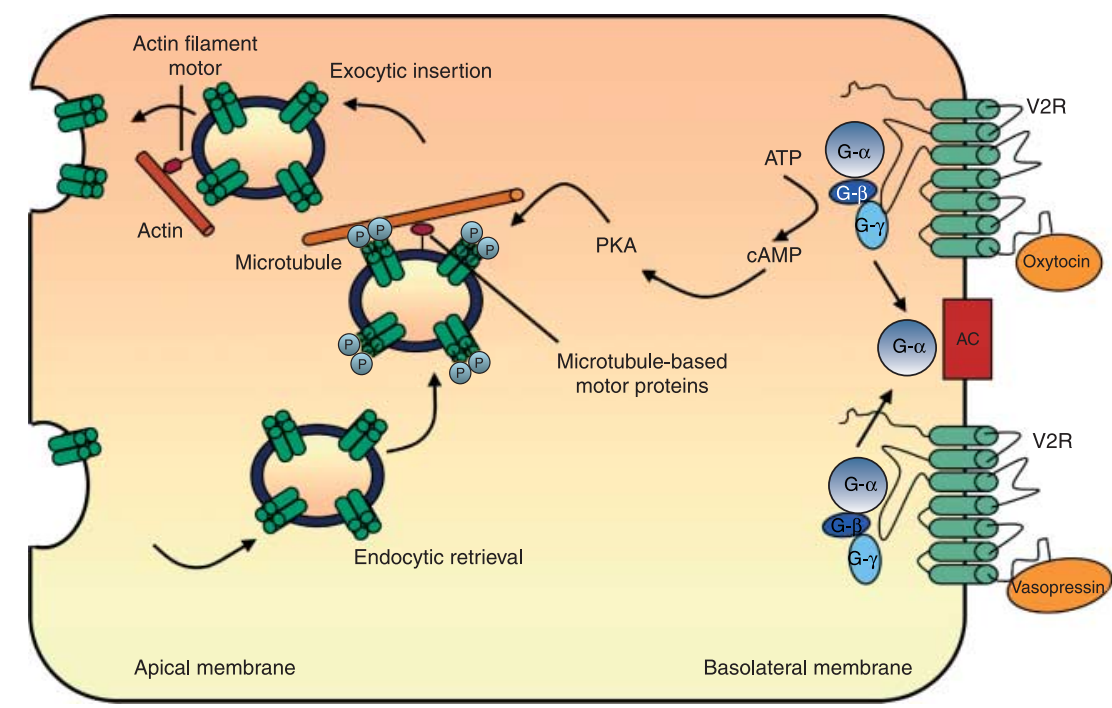

Figure 3 Signaling cascades involved in Vp/oxytocin-triggered trafficking of AQP2 into the apical cell membrane of collecting duct principal cells. Vp/oxytocin binds to G proteincoupled V2R on the basolateral membrane to stimulate intracellular cAMP production. This initiates the synthesis of intracellular cAMP via the $G_{s} / A C$ system. The increased cAMP activates PKA which phosphorylate $\mathrm{Ser}^{256}$ of AQP2. Microtubules and microtubule-based motor proteins as well as actin filaments and actin filament binding proteins are necessary for vesicle movement toward the membrane (Tamma et al. 2003). This V2R mediated signaling pathway eventually leads to the exocytotic insertion of AQP2-bearing vesicles into the apical plasma membrane, resulting in higher water permeability in the collecting duct and hence water movement from lumen to the interstitium for water reabsorption in the kidney.

with lower affinity (Terashima et al. 1999), several studies have suggested the possibility that the antidiuretic action of oxytocin is mediated via V2R. For example, acute elevation of plasma oxytocin could upregulate AQP2 and downregulated V2R transcripts without affecting the plasma Vp level (Terashima et al. 1999). Although both oxytocin receptor and the V2R transcripts were found by RT-PCR in rat collecting duct where the process of urine concentration takes place, in vitro microperfusion of rat IMCD showed that only the V2R antagonist [d(CH2)5(1),D-Ile2,Ile4,Arg8]Vp, but not oxytocin receptor antagonists could block the hydro-osmotic response to $200 \mathrm{pM}$ oxytocin, suggesting actions of oxytocin is mediated by V2R (Chou et al. 1995a). This effect of V2R antagonist was repeated in several studies (Pouzet et al. 2001, Li et al. 2008), together with the data of oxytocin and V2R antagonist on AQP2 translocation in rat collecting duct, provide further evidence that V2R, but not oxytocin receptor, mediates oxytocin's action (Jeon et al. 2003).

\section{Disorder of body water homeostasis}

Disorders related to water and sodium homeostasis are common problems encountered in clinical practice and can be divided into hyperosmolar and hypoosmolar disorders. Hyperosmolar and hypoosmolar disorders are characterized by a deficiency and an excess, respectively, of body water relative to body solute. Representatives of such disorders are diabetes insipidus and the syndrome of inappropriate secretion of antidiuretic hormone (SIADH).

\section{Diabetes insipidus}

Diabetes insipidus is a syndrome characterized by a failure of urine to concentrate leading to symptoms of polyuria and polydipsia. It is classified into CDI and NDI depending on whether it is a result of decreased secretion of $\mathrm{Vp}$ or an impaired response of the kidney to $\mathrm{Vp}$, respectively. CDI is due to the disruption of the hypothalamic-neurohypophysial axis by a variety of acquired and congenital causes, all of which lead to insufficient production of $\mathrm{Vp}$, while NDI is caused by a reduced or absent response to $\mathrm{Vp}$. The genetic forms of NDI are results of mutations in the genes coding for the V2R or AQP2. Among all NDI patients, 90\% have various mutations in the $\mathrm{V} 2 \mathrm{R}$ gene, which resides on $\mathrm{Xq} 28$ and hence is prevalent in males. The remaining $10 \%$ patients have mutations of the AQP2 gene, which is situated on $12 \mathrm{q} 13$ and thus is inherited in an autosomal manner (Deen et al. 1994a, Saito et al. 1995). For the X-linked congenital NDI, V2R gene 
mutations can be divided into five different classes according to their cellular fate (Fig. 4; Robben et al. 2005). Class I leads to unstable RNA, resulting in the formation of an incomplete protein. Receptors in Class II have protein misfolding leading to endoplasmic reticulum (ER) retention and hence degradation within endosomes. Class III mutations produce receptors that are not capable of transducing signals via $\mathrm{G}$ proteins. Class IV mutants are unable to bind Vp. Finally, Class V mutations lead to missorting of receptors in the cell. All these mutations lead to the absence of functional receptors on cell surface and hence impairment in water reabsorption.

\section{Autosomal recessive and dominant NDI}

For the remaining $10 \%$ patients of NDI, the disorder can be either inherited as an autosomal recessive or as an autosomal dominant trait. The disease stems from mutations in AQP2 gene which is mapped to $12 \mathrm{q} 13$ (Deen et al. 1994a, Saito et al. 1995). Of these patients, more than $90 \%$ are autosomal recessive in which mutant AQP2 proteins are misfolded, trapped in the ER, and subject to rapid proteasomal degradation (Deen et al. 1995, Mulders et al. 1997, Tamarappoo \& Verkman 1998, Marr et al. 2001, 2002, Lin et al. 2002). Autosomal dominant inheritance is the least prominent form of NDI. Expression studies revealed that AQP2 in these patients are properly folded, however, due to the mutation, the interaction with the wild type AQP2 cause the missorting of the wild type-AQP2/mutant complex (Mulders et al. 1998, Kamsteeg et al. 1999, 2003, Kuwahara et al. 2001). Mutations are found within the C-terminal tail of the protein (Robben et al. 2006), revealing the importance of this segment in the trafficking of AQP2.

\section{Syndrome of SIADH}

SIADH, or syndrome of inappropriate secretion of antidiuretic hormone, frequently occurs in hospitalized patients, and is characterized by hyponatremia and the production of concentrated urine. Studies of Vp release in response to hypertonic saline infusion in patients with SIADH reveal 4 patterns of abnormal Vp secretion (Multz 2007). Type $\mathrm{A}$, the most common, occurs in $\sim 40 \%$ of patients and involves excessive, erratic and ectopic secretion of Vp unrelated to plasma osmolality. Type B found in $\sim 30 \%$ of patients is characterized by continued water excretion at a lower set point of plasma osmolality. Type $\mathrm{C}$, also occurs in $\sim 30 \%$ of patients, is defined by a constant leak of $\mathrm{Vp}$. The abnormality is possibly due to a loss of inhibitory osmoregulatory mechanism or damage to neurohypophysis mechanisms. For type D (5-10\%), the cause is not completely understood. In this type of patient, normal osmoregulation of plasma Vp was observed and some of them, in particular infants, appear to suffer nephrogenic syndrome of inappropriate antidiuresis, which is a recently described genetic disease caused by V2R activating mutations resulting in

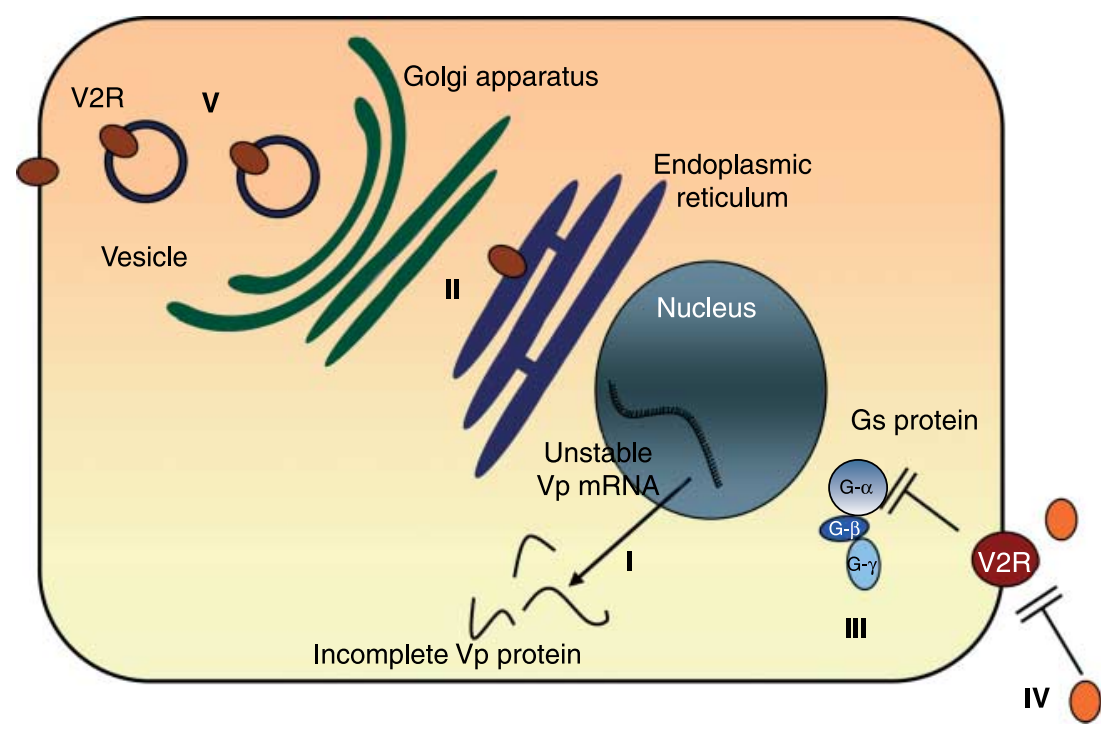

Figure 4 Schematic representation of five different classes (I-V) of V2R mutation in nephrogenic diabetes insipidus (NDI). Class I mutations lead to unstable RNA, resulting in the formation of incomplete protein. Class II mutations involve endoplasmic reticulum (ER) retention of full-length proteins. Class III mutations result in inefficient $\mathrm{G}$ protein-coupling, Class IV mutants are unable to bind Vp. Finally, Class V mutations lead to missorting of proteins. 
hyponatremia (Feldman et al. 2005). The clinical presentations resemble those typically observed in patients with SIADH but with undetectable arginine vasopressin (AVP) levels. In other type D patients, it may be due to abnormal control of AQP2 in renal collecting tubules (Verbalis et al. 1998).

\section{Future perspective}

A study showed that $S C T R^{-/-}$mice display pathological symptoms of NDI. Histological examination showed that $S C T R^{-/-}$mice exhibited abnormalities in the renal cortex and the medulla, characterized by increased mesangial area, enlarged urinary space, and frequent tubular dilation and hypertrophy in the collecting tubules of the medullary region. Quantification by real-time PCR revealed significant increases in the transcript levels of interleukin-10, tumor necrosis factor $\alpha$, E-selectin, and osteopontin which are the proinflammatory cytokines indicating the inflammation and cell recruitment in diabetic nephropathy (Chu et al. 2007). Secretin has also been reported to cause an increase in insulin secretion (Enk 1976). In both normal and obese non-diabetics groups, i.v. injection of secretin elicits an increase in insulin concentrations in the cubital vein (Enk et al. 1976). In another study, secretin infusion was found to augment immunoreactive insulin in the blood and improve glucose tolerance (Dupre et al. 1975). Similar results have also been reported in a transgenic mice study in which a higher blood glucose level was observed in $\mathrm{SCTR}^{-/-}$mice (Chu et al. 2007). The reported effects of secretin on insulin secretion together with the pathological features observed in the kidneys of $S C T R^{-/-}$mice all point to abnormalities in the production and/or release of this hormone, as well as the disturbance of its receptor, which may manifest into the renal and metabolic perturbations observed in diabetes and SIADH. The anti-diuretic action of secretin and the pathological symptoms of NDI observed in $\mathrm{SCTR}^{-/-}$mice suggest that dysfunction of secretin and receptor axis could be a class of NDI. In summary, in a growing body of evidence, reviewed here, secretin can trigger intracellular redistribution of AQP2 to the apical membrane and therefore serve as a potential candidate in treating X-linked NDI with defective V2R signaling. Hence, further investigation is needed to elucidate the potential role of secretin as a target for prevention and/or therapeutic intervention of these diseases.

\section{Declaration of interest}

The authors declare that there is no conflict of interest that could be perceived as prejudicing the impartiality of the research reported.

\section{Funding}

This work was supported by a research grant from Research Grant Council HKU 7501/05 M and 7566/06 M to BKC Chow.

\section{References}

Ahmad AJ, Clark EH \& Jacobs HS 1975 Water intoxication associated with oxytocin infusion. Postgraduate Medical Journal 51 249-252.

Alfredo L, Viteri AL, Poppell JW, Lasater JM \& Dyck WP 1975 Renal response to secretin. Journal of Applied Physiology 38 661-664.

van Balkom BW, Savelkoul PJ, Markovich D, Hofman E, Nielsen S, van der Sluijs P \& Deen PM 2002 The role of putative phosphorylation sites in the targeting and shuttling of the aquaporin-2 water channel. Journal of Biological Chemistry 277 41473-41479.

Barbezat GO, Isenberg JI \& Grossman MI 1972 Diuretic action of secretin in dog. Proceedings of the Society for Experimental Biology and Medicine 139 211-215.

Baron DN, Newman F \& Warrick A 1958 The effects of secretin on urinary volume and electrolytes in normal subjects and patients with chronic pancreatic disease. Experientia 14 30-32.

Bauman JW Jr 1965 Effect of hypophysectomy on the renal concentrating ability of the rat. Endocrinology 77 496-500.

Breton S \& Brown D 1998 Cold-induced microtubule disruption and relocalization of membrane proteins in kidney epithelial cells. Journal of the American Society of Nephrology 9 155-166.

Brooks FP \& Pickford MT 1958 The effect of posterior pituitary hormones on the excerion of electrolytes in dogs. Journal of Physiology 3 468-493.

Brown D 2003 The ins and outs of aquaporin-2 trafficking. American Journal of Physiology. Renal Physiology 284 F893-F901.

Capurro Cea 2001 Vasopressin regulates water flow in a rat cortical collecting duct cell line not containing known aquaporins. Journal of Membrane Biology 179 63-70.

Charlton CG, Quirion R, Handelmann GE, Miller RL, Jensen RT, Finkel MS \& O'Donohue TL 1986 Secretin receptors in the rat kidney: adenylate cyclase activation and renal effects. Peptides 7 865-871.

Chou CL, DiGiovanni SR, Mejia R, Nielsen S \& Knepper MA $1995 a$ Oxytocin as an antidiuretic hormone. I. Concentration dependence of action. American Journal of Physiology 269 F70-F77.

Chou CL, DiGiovanni SR, Luther A, Lolait SJ \& Knepper MA $1995 b$ Oxytocin as an antidiuretic hormone. II. Role of V2 vasopressin receptor. American Journal of Physiology 269 F78-F85.

Chu JY, Chung SC, Lam AK, Tam S, Chung SK \& Chow BK 2007 Phenotypes developed in secretin receptor-null mice indicated a role for secretin in regulating renal water reabsorption. Molecular and Cellular Biology 27 2499-2511.

Coleman RA, Wu DC, Liu J \& Wade JB 2000 Expression of aquaporins in the renal connecting tubule. American Journal of Physiology. Renal Physiology 279 F874-F883.

Cross RB, Dicker SE, Kitchin AH, Lloyd S \& Pickford M 1960 The effect of oxytocin on the urinary excretion of water and electrolytes in man. Journal of Physiology 153 553-561.

Deen PM, Weghuis DO, Sinke RJ, Geurts van Kessel A, Wieringa B \& van Os CH 1994a Assignment of the human gene for the water channel of renal collecting duct aquaporin 2 (AQP2) to chromosome 12 region $\mathrm{q} 12 \rightarrow \mathrm{q} 13$. Cytogenetics and Cell Genetics 66 260-262.

Deen PM, Verdijk MA, Knoers NV, Wieringa B, Monnens LA, van Os CH \& van Oost BA $1994 b$ Requirement of human renal water channel aquaporin-2 for vasopressin-dependent concentration of urine. Science 264 92-95. 
Deen PM, Croes H, van Aubel RA, Ginsel LA \& van Os CH 1995 Water channels encoded by mutant aquaporin-2 genes in nephrogenic diabetes insipidus are impaired in their cellular routing. Journal of Clinical Investigation 95 2291-2296.

Dicker SE \& Heller H 1946 The renal action of posterior pituitary extract and its fractions as analysed by clearance experiments on rats. Journal of Physiology 104 353-360.

Dragstedt CA \& Owen SE 1931 The diuretic action of secretin preparation. American Journal of Physiology 97 276-281.

Dupre J, Chisholm DJ, McDonald TJ \& Rabinovitch A 1975 Effects of secretin on insulin secretion and glucose tolerance. Canadian Journal of Physiology and Pharmacology 53 1115-1121.

Ecelbarger CA, Terris J, Frindt G, Echevarria M, Marples D, Nielsen S \& Knepper MA 1995 Aquaporin-3 water channel localization and regulation in rat kidney. American Journal of Physiology $\mathbf{2 6 9}$ F663-F672.

Ecelbarger CA, Kim GH, Terris J, Masilamani S, Mitchell C, Reyes I, Verbalis JG \& Knepper MA 2000 Vasopressin-mediated regulation of epithelial sodium channel abundance in rat kidney. American Journal of Physiology. Renal Physiology 279 F46-F53.

Enk B 1976 Secretin-induced insulin response. II. Dose-response relation. Acta Endocrinologica 82 312-317.

Enk B, Lund B, Schmidt A \& Deckert T 1976 Secretin-induced insulin response. I. Cubital insulin concentration in normal, obese and pancreatectomized patients, including portal insulin concentration in normals after secretin. Acta Endocrinologica 82 306-311.

Feldman BJ, Rosenthal SM, Vargas GA, Fenwick RG, Huang EA, Matsuda-Abedini M, Lustig RH, Mathias RS, Portale AA, Miller WL et al. 2005 Nephrogenic syndrome of inappropriate antidiuresis. New England Journal of Medicine 352 1884-1890.

Feraille E, Mordasini D, Gonin S, Deschenes G, Vinciguerra M, Doucet A, Vandewalle A, Summa V, Verrey F \& Martin PY 2003 Mechanism of control of Na, K-ATPase in principal cells of the mammalian collecting duct. Annals of the New York Academy of Science 986 570-578.

Fushimi K, Sasaki S \& Marumo F 1997 Phosphorylation of serine 256 is required for cAMP-dependent regulatory exocytosis of the aquaporin-2 water channel. Journal of Biological Chemistry 272 14800-14804.

Gimenez I \& Forbush B 2003 Short-term stimulation of the renal $\mathrm{Na}-\mathrm{K}-\mathrm{Cl}$ cotransporter (NKCC2) by vasopressin involves phosphorylation and membrane translocation of the protein. Journal of Biological Chemistry 278 26946-26951.

Hozawa S, Holtzman EJ \& Ausiello DA 1996 cAMP motifs regulating transcription in the aquaporin 2 gene. American Journal of Physiology 270 C1695-C1702.

Ishibashi K, Sasaki S, Fushimi K, Uchida S, Kuwahara M, Saito H, Furukawa T, Nakajima K, Yamaguchi Y \& Gojobori T 1994 Molecular cloning and expression of a member of the aquaporin family with permeability to glycerol and urea in addition to water expressed at the basolateral membrane of kidney collecting duct cells. PNAS 91 6269-6273.

Jeon US, Joo KW, Na KY, Kim YS, Lee JS, Kim J, Kim GH, Nielsen S, Knepper MA \& Han JS 2003 Oxytocin induces apical and basolateral redistribution of aquaporin-2 in rat kidney. Nephron. Experimental Nephrology 93 e36-e45.

Joo KW, Jeon US, Kim GH, Park J, Oh YK, Kim YS, Ahn C, Kim S, Kim SY \& Lee JS 2004 Antidiuretic action of oxytocin is associated with increased urinary excretion of aquaporin-2. Nephrology, Dialysis, Transplantation: Official Publication of the European Dialysis and Transplant Association - European Renal Association 19 2480-2486.

Kamsteeg EJ, Wormhoudt TA, Rijss JP, van Os CH \& Deen PM 1999 An impaired routing of wild-type aquaporin-2 after tetramerization with an aquaporin-2 mutant explains dominant nephrogenic diabetes insipidus. EMBO Journal 18 2394-2400.
Kamsteeg EJ, Bichet DG, Konings IB, Nivet H, Lonergan M, Arthus MF, van Os CH \& Deen PM 2003 Reversed polarized delivery of an aquaporin-2 mutant causes dominant nephrogenic diabetes insipidus. Journal of Cell Biology 163 1099-1109.

Klussmann E \& Rosenthal W 2001 Role and identification of protein kinase A anchoring proteins in vasopressin-mediated aquaporin-2 translocation. Kidney International 60 446-449.

Kuwahara M, Iwai K, Ooeda T, Igarashi T, Ogawa E, Katsushima Y, Shinbo I, Uchida S, Terada Y, Arthus MF et al. 2001 Three families with autosomal dominant nephrogenic diabetes insipidus caused by aquaporin-2 mutations in the C-terminus. American Journal of Human Genetics 69 738-748.

Li JP, Chang TM \& Chey WY 2001 Roles of 5-HT receptors in the release and action of secretin on pancreatic secretion in rats. American Journal of Physiology. Gastrointestinal and Liver Physiology 280 G595-G602.

Li C, Wang W, Summer SN, Cadnapaphornchai MA, Falk S, Umenishi F \& Schrier RW 2006 Hyperosmolality in vivo upregulates aquaporin 2 water channel and $\mathrm{Na}-\mathrm{K}-2 \mathrm{Cl}$ co-transporter in Brattleboro rats. Journal of the American Society of Nephrology: JASN 17 1657-1664.

Li C, Wang W, Summer SN, Westfall TD, Brooks DP, Falk S \& Schrier RW 2008 Molecular mechanisms of antidiuretic effect of oxytocin. Journal of the American Society of Nephrology: JASN 19 225-232.

Lin SH, Bichet DG, Sasaki S, Kuwahara M, Arthus MF, Lonergan M \& Lin YF 2002 Two novel aquaporin-2 mutations responsible for congenital nephrogenic diabetes insipidus in Chinese families. Journal of Clinical Endocrinology and Metabolism 87 2694-2700.

Loffing J, Loffing-Cueni D, Macher A, Hebert SC, Olson B, Knepper MA, Rossier BC \& Kaissling B 2000 Localization of epithelial sodium channel and aquaporin-2 in rabbit kidney cortex. American Journal of Physiology. Renal Physiology 278 F530-F539.

Lyness J, Robinson AG, Sheridan MN \& Gash DM 1985 Antidiuretic effects of oxytocin in the Brattleboro rat. Experientia 41 1444-1446.

Ma T, Song Y, Yang B, Gillespie A, Carlson EJ, Epstein CJ \& Verkman AS 2000 Nephrogenic diabetes insipidus in mice lacking aquaporin3 water channels. PNAS 97 4386-4391.

Marples D, Knepper MA, Christensen EI \& Nielsen S 1995 Redistribution of aquaporin-2 water channels induced by vasopressin in rat kidney inner medullary collecting duct. American Journal of Physiology 269 C655-C664.

Marr N, Kamsteeg EJ, van Raak M, van Os CH \& Deen PM 2001 Functionality of aquaporin-2 missense mutants in recessive nephrogenic diabetes insipidus. Pflügers Archiv: European Journal of Physiology 442 73-77.

Marr N, Bichet DG, Hoefs S, Savelkoul PJ, Konings IB, De Mattia F, Graat MP, Arthus MF, Lonergan M, Fujiwara TM et al. 2002 Cellbiologic and functional analyses of five new aquaporin-2 missense mutations that cause recessive nephrogenic diabetes insipidus. Journal of the American Society of Nephrology 13 2267-2277.

Matsumura Y, Uchida S, Rai T, Sasaki S \& Marumo F 1997 Transcriptional regulation of aquaporin-2 water channel gene by cAMP. Journal of the American Society of Nephrology 8 861-867.

Mulders SM, Knoers NV, Van Lieburg AF, Monnens LA, Leumann E, Wuhl E, Schober E, Rijss JP, Van Os CH \& Deen PM 1997 New mutations in the AQP2 gene in nephrogenic diabetes insipidus resulting in functional but misrouted water channels. Journal of the American Society of Nephrology 8 242-248.

Mulders SM, Bichet DG, Rijss JP, Kamsteeg EJ, Arthus MF, Lonergan M, Fujiwara M, Morgan K, Leijendekker R, van der Sluijs P et al. 1998 An aquaporin-2 water channel mutant which causes autosomal dominant nephrogenic diabetes insipidus is retained in the Golgi complex. Journal of Clinical Investigation 102 57-66.

Multz AS 2007 Vasopressin dysregulation and hyponatremia in hospitalized patients. Journal of Intensive Care Medicine 22 216-223.

Nielsen S, DiGiovanni SR, Christensen EI, Knepper MA \& Harris HW 1993 Cellular and subcellular immunolocalization of vasopressinregulated water channel in rat kidney. PNAS 90 11663-11667. 
Nielsen S, Chou CL, Marples D, Christensen EI, Kishore BK \& Knepper MA 1995 Vasopressin increases water permeability of kidney collecting duct by inducing translocation of aquaporin-CD water channels to plasma membrane. PNAS 92 1013-1017.

Oektedalen O, Opstad PK \& OB SdM 1982 Secretin - a new stress hormone? Regulatory Peptides 4 213-219.

Ohta M, Funakoshi S, Kawasaki T \& Itoh N 1992 Tissue-specific expression of the rat secretin precursor gene. Biochemical and Biophysical Research Communications 183 390-395.

Pouzet B, Serradeil-Le Gal C, Bouby N, Maffrand JP, Le Fur G \& Bankir L 2001 Selective blockade of vasopressin V2 receptors reveals significant V2-mediated water reabsorption in Brattleboro rats with diabetes insipidus. Nephrology, Dialysis, Transplantation: Official Publication of the European Dialysis and Transplant Association European Renal Association 16 725-734.

Robben JH, Knoers NV \& Deen PM 2005 Characterization of vasopressin V2 receptor mutants in nephrogenic diabetes insipidus in a polarized cell model. American Journal of Physiology. Renal Physiology 289 F265-F272.

Robben JH, Knoers NV \& Deen PM 2006 Cell biological aspects of the vasopressin type-2 receptor and aquaporin 2 water channel in nephrogenic diabetes insipidus. American Journal of Physiology. Renal Physiology 291 F257-F270.

Rojek A, Fuchtbauer EM, Kwon TH, Frokiaer J \& Nielsen S 2006 Severe urinary concentrating defect in renal collecting duct-selective AQP2 conditional-knockout mice. PNAS 103 6037-6042.

Roudier N, Ripoche P, Gane P, Le Pennec PY, Daniels G, Cartron JP \& Bailly P 2002 AQP3 deficiency in humans and the molecular basis of a novel blood group system, GIL. Journal of Biological Chemistry 277 $45854-45859$.

Saito F, Sasaki S, Chepelinsky AB, Fushimi K, Marumo F \& Ikeuchi T 1995 Human AQP2 and MIP genes, two members of the MIP family, map within chromosome band 12q13 on the basis of two-color FISH. Cytogenetics and Cell Genetics 68 45-48.

Sands JM 2003 Molecular mechanisms of urea transport. Journal of Membrane Biology 191 149-163.

Star RA, Nonoguchi H, Balaban R \& Knepper MA 1988 Calcium and cyclic adenosine monophosphate as second messengers for vasopressin in the rat inner medullary collecting duct. Journal of Clinical Investigation 81 1879-1888.

Tamarappoo BK \& Verkman AS 1998 Defective aquaporin-2 trafficking in nephrogenic diabetes insipidus and correction by chemical chaperones. Journal of Clinical Investigation 101 $2257-2267$.
Tamma G, Klussmann E, Procino G, Svelto M, Rosenthal W \& Valenti G 2003 cAMP-induced AQP2 translocation is associated with RhoA inhibition through RhoA phosphorylation and interaction with RhoGDI. Journal of Cell Science 116 1519-1525.

Terashima Y, Kondo K \& Oiso Y 1999 Administration of oxytocin affects vasopressin V2 receptor and aquaporin-2 gene expression in the rat. Life Sciences 64 1447-1453.

Terris J, Ecelbarger CA, Marples D, Knepper MA \& Nielsen S 1995 Distribution of aquaporin-4 water channel expression within rat kidney. American Journal of Physiology 269 F775-F785.

Thomson WB 1960 The effect of oxytocin and vasopressin and of phenylalanin-oxytocin on the urinary excretion of water and electrolytes in man. American Journal of Optometry and Physiological Optics 150 284-294.

Tietz PS, Marinelli RA, Chen XM, Huang B, Cohn J, Kole J, McNiven MA, Alper S \& LaRusso NF 2003 Agonist-induced coordinated trafficking of functionally related transport proteins for water and ions in cholangiocytes. Journal of Biological Chemistry 278 20413-20419.

Ulrich CD II, Holtmann M \& Miller LJ 1998 Secretin and vasoactive intestinal peptide receptors: members of a unique family of $\mathrm{G}$ protein-coupled receptors. Gastroenterology 114 382-397.

Verbalis JG, Mangione MP \& Stricker EM 1991 Oxytocin produces natriuresis in rats at physiological plasma concentrations. Endocrinology 3 1317-1322.

Verbalis JG, Murase T, Ecelbarger CA, Nielsen S \& Knepper MA 1998 Studies of renal aquaporin-2 expression during renal escape from vasopressin-induced antidiuresis. Advances in Experimental Medicine and Biology 449 395-406.

Waldum HL, Sundsfjord JA, Aanstad U \& Burhol PG 1980 The effect of secretin on renal haemodynamics in man. Scandinavian Journal of Clinical and Laboratory Investigation 40 475-478.

Yang B, Gillespie A, Carlson EJ, Epstein CJ \& Verkman AS 2001 Neonatal mortality in an aquaporin-2 knock-in mouse model of recessive nephrogenic diabetes insipidus. Journal of Biological Chemistry 276 2775-2779.

Yang B, Zhao D, Qian L \& Verkman AS 2006 Mouse model of inducible nephrogenic diabetes insipidus produced by floxed aquaporin-2 gene deletion. American Journal of Physiology. Renal Physiology 291 F465-F472.

Received in final form 16 March 2009

Accepted 23 March 2009

Made available online as an Accepted Preprint 23 March 2009 